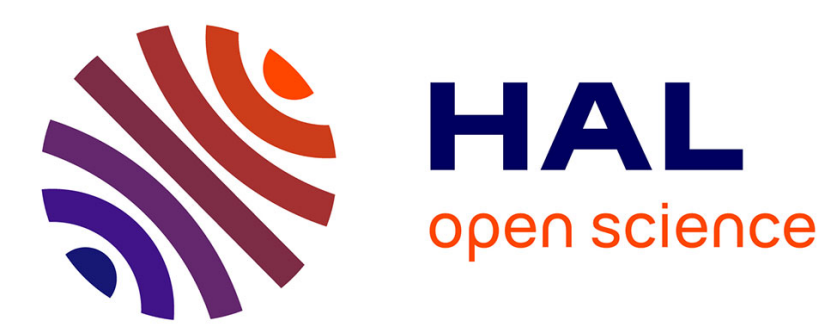

\title{
Host-guest chemistry of self-assembling supramolecular capsules in the gas phase
}

Christoph A. Schalley

\section{To cite this version:}

Christoph A. Schalley. Host-guest chemistry of self-assembling supramolecular capsules in the gas phase. Supramolecular Chemistry, 2008, 20 (01-02), pp.117-128. 10.1080/10610270701771800 . hal00513523

\section{HAL Id: hal-00513523 \\ https://hal.science/hal-00513523}

Submitted on 1 Sep 2010

HAL is a multi-disciplinary open access archive for the deposit and dissemination of scientific research documents, whether they are published or not. The documents may come from teaching and research institutions in France or abroad, or from public or private research centers.
L'archive ouverte pluridisciplinaire HAL, est destinée au dépôt et à la diffusion de documents scientifiques de niveau recherche, publiés ou non, émanant des établissements d'enseignement et de recherche français ou étrangers, des laboratoires publics ou privés. 


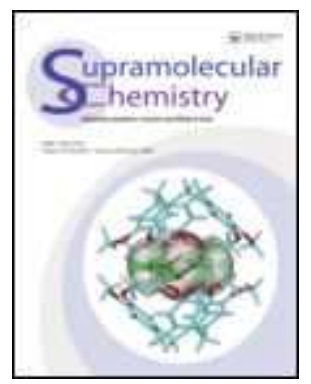

\section{Host-guest chemistry of self-assembling supramolecular capsules in the gas phase}

\begin{tabular}{|c|c|}
\hline Journal: & Supramolecular Chemistry \\
\hline Manuscript ID: & GSCH-2007-0111.R1 \\
\hline Manuscript Type: & Special Issue Paper \\
\hline $\begin{array}{l}\text { Date Submitted by the } \\
\text { Author: }\end{array}$ & 23-Oct-2007 \\
\hline Complete List of Authors: & Schalley, Christoph; Freie Universität Berlin \\
\hline Keywords: & $\begin{array}{l}\text { calixarene, mass spectrometry, gas-phase chemistry, hydrogen- } \\
\text { bonded capsules, hexameric capsules }\end{array}$ \\
\hline \multicolumn{2}{|c|}{$\begin{array}{l}\text { Note: The following files were submitted by the author for peer review, but cannot be converted } \\
\text { to PDF. You must view these files (e.g. movies) online. }\end{array}$} \\
\hline $\begin{array}{l}\text { Figure08.cdx } \\
\text { Figure11.cdx }\end{array}$ & \\
\hline
\end{tabular}

\section{(s) ScholarONE" \\ Manuscript Central}




\section{Introduction}

The encapsulation of appropriately sized, shaped, and functionalized guest molecules into reversibly formed, self-assembling supramolecular capsules ${ }^{1}$ can be considered a model for substrate recognition by enzymes. The capsules discussed in this mini-review are held together by weak interactions: hydrogen bonding between two or more complementary subunits, cation- $\pi$ interactions between aromatic rings in the capsule walls and the guest cation, Van-der-Waals interactions between capsule and guest as well as the filling of space.

This mini-review will focus on hydrogenbonded capsules with different hydrogenbonding patterns. Quite some insight can be gained with respect to their formation, their secondary structure, their monomer exchange behaviour, and the forces that stabilize the capsules through mass spectrometric experiments. ${ }^{2}$

In this context, it is important to note that the potential of mass spectrometry goes far beyond mere analytical characterization. ${ }^{3}$ Through tandem MS experiments in the gas phase, new insights becomes available, which cannot be gained from solution experiments. In the gas phase, no environment is present and the intrinsic properties of the ions under study can be evaluated. Since no exchange processes are possible, the gas phase offers also a completely new view on reactivity of non-covalent species which cannot be obtained from solution experiments. 


\section{Molecular Softballs: Introducing the Experimental Methodology}

The molecular softballs, named according to their topology after the larger brother of an American baseball, have been synthesized and characterized in the Rebek group starting in the early 1990's. ${ }^{4-6}$ The selfcomplementary monomers $\mathbf{1}$ - $\mathbf{4}$ and control compound 5 (Figure 1) basically consist of two glycoluril moieties connected to each other by spacers of different length determining the size of the inner cavity of dimeric 1•1 - $\mathbf{4 \bullet 4}$ (Figure 2).

The formation of the dimeric capsules $\mathbf{1} \mathbf{1}$ $\mathbf{4 \cdot 4}$ has been observed by ${ }^{1} \mathrm{H}$ NMR spectroscopy in aprotic organic solvents like chloroform or xylene. ${ }^{1,4,7}$ For the detection of the capsules by ESI mass spectrometry, the inclusion of charged guests such as quaternary ammonium ions represents the most convenient way of ion labeling. For the softballs, N-methyl-quinuclidinium $\mathbf{6 a}^{+}$ and tetraethylammonium $\mathbf{7}^{+}$are perfectly suited. This ion labeling strategy does not interfere with the seam of hydrogen bonding as long as weakly coordinating counterion such as $\mathrm{BF}_{4}^{-}$and $\mathrm{PF}_{6}^{-}$are used. Furthermore, this approach is consistent with the use of non-protic solvents which would not compete with the hydrogen bonds and destroy the capsules. In addition, no synthetic modifications of the capsules are required. Cations $\mathbf{6 a}^{+}$and $7^{+}$were chosen as guests due to their structural and spatial congruency with the capsule interior cavity. ${ }^{6,8}$

As expected, the ESI mass spectra of chloroform solutions of $\mathbf{6 a}^{+} \mathrm{BF}_{4}^{-}$and one of the monomers 1 - 4 showed 2:1 complexes of capsule monomers and cationic guest as the base peaks (Figure 3). ${ }^{9}$ In addition, signals for dimeric capsules with enclosed chloroform are observed, which receive their positive charges from background sodium. Comparison of the calculated and experimental isotope patterns confirms the correct elemental composition. Substitution of the methyl group in $\mathbf{6 a}^{+}$by a $\mathrm{CD}_{3}$ group $\left(\mathbf{6 b}^{+}\right)$shifts the signals for the capsules by $\Delta \mathrm{m}=3$ making sure that only one guest is present.

Control compounds such as the methoxylated monomer 5 or an S-shaped monomer (Figure 4) do not show any signals for dimer-guest complexes, because they are not able to form capsules due to blocked hydrogen bonds and the lack of well preorganized binding sites, respectively. This finding clearly points to a capsular structure, as does the size selectivity of the dimers for guest cations of the right sizes. If large guest cations are used that do not fit into the cavity (e.g. tetrabutylammonium $\mathbf{8}^{+}$), no dimer-guest complexes are observed either. Addition of competitive solvents like methanol destroys the seam of hydrogen bonds and all signals of 2:1 complexes vanish in favour of signals for protonated monomers. This confirms the hydrogen-bonded nature of the dimer-guest ions.

The reversible formation of hydrogenbridged dimers is also revealed through the formation of heterodimers, when two preformed homodimeric capsules are mixed (Figure 5). If they possess spacers very different in length, the heterodimer is formed in abundances far lower than statistically expected (Figure 5a). If the spacers incorporated in the monomers are however similar in length, they form heterodimers 
in a nearly statistical 1:2:1 ratio (Figure $5 b$ ). Consequently, a precise geometric fit is required for stable heterodimers to form. Otherwise, the capsules tend to self-sort. The requirement of a precise geometric fit of the capsule halves and the size selectivity for appropriate guests together with the necessity of suitable preorganization of the binding sites is good evidence for a capsular structure. However, so far the mass spectrometer was used as a detector for solution-phase assembly.

In order to further determine the structure of the 2:1 host-guest complexes in the gas phase, in-source collision experiments were performed. Intriguingly, losses of $\mathrm{C}_{2} \mathrm{H}_{4}$ and $\mathrm{C}_{5} \mathrm{H}_{12}$ losses are observed. Figure 6 shows possible pathways that rationalize these fragmentation reactions in terms of energetically quite favourable processes. The products of these reactions are a conjugated double bond formed by 1,2elimination within one of the solubilizing side chains and an aromatic ring in the softball's central unit generated through a retro-Diels-Alder reaction.

These results are not in line with a guest cation weakly bound to the periphery of the capsule. They can, however, be understood easily, if the cation is bound inside. Opening the capsule for guest release increases the barrier significantly, since not only the binding energy of the guest inside must be overcome, but in addition the seam of hydrogen bonds must be opened to a significant extent. Consequently, these gas-phase experiments show the dimerguest complex to be a capsule even in the gas phase after the ionization process. The mass spectrometric experiments are in agreement with results from NMR spec- troscopy which provide evidence for cation encapsulation in solution. For the cation signals, typical up-field shifts are observed.

\section{American Footballs: Tetramer For- mation Supported by Cation- $\pi$ Interac- tions}

The softballs have been used as an example to introduce the mass spectrometric experiments that have been developed to assess the structure of a hydrogen-bonded capsule: The ion labeling strategy, sizeselectivity arguments, preorganization of binding sites, heterodimer formation, and fragmentation reactions in the gas phase all contribute to this goal.

We can now apply this methodology to other types of hydrogen-bonded capsules such as the molecular football (Figure 7). ${ }^{10}$ The football monomer again bears a glycoluril moiety. On the other end, the softball center piece is replaced with a sulfondiamide moiety which can act as hydrogen bond donor and acceptor. Through the sulfonyl group, the required curvature is provided. This monomer is insoluble in nonpolar solvents and becomes only soluble, when a suitable guest is present which templates the formation of a head - to - tail - to - head -to-tail tetramer with a fully closed surface. The space inside the cavity approximates that of the smaller softballs.

Mass spectrometric experiments reveal a clear size-selectivity for encapsulation of suitable guests when a larger number of ammonium ions is used pairwise in competition experiments.

Also, the importance of cation- $\pi$ interactions ${ }^{11}$ can be examined with the tetrameric footballs. All dipoles are oriented more or 
less tangentially on the capsule surface. Therefore, the positive and negative ends of these dipoles are similarly remote from the guest cation and cation-dipole forces likely cancel rather than playing a pivotal role for cation binding. Nevertheless, the charge on the guests increases the binding strength to the capsule cavity significantly. Figure 8 shows two guest pairs of almost identical size and shape $\left(\mathbf{1 0 a} / \mathbf{1 0 b} \mathbf{b}^{+}\right.$and $\mathbf{1 1 a} / \mathbf{1 1 b}^{+}$). One of each pair is neutral with a quaternary carbon atom, where the other has an ammonium nitrogen. NMR experiments with 1:80:2 mixtures of capsule, neutral guest, and ammonium ion do not show any sign of encapsulation of the neutral guest, while the signals for the encapsulated cation integrate $1: 1$ with respect to the capsule signals. This leads to the conclusion that cation- $\pi$ interactions must be important for driving guest encapsulation.

\section{Flexiballs: The Importance of En- tropic Factors}

In order to modularize the synthesis of capsules and at the same time achieve capsules with larger cavities and functional groups (e.g. amide $\mathrm{N}-\mathrm{H}$ or $\mathrm{C}=\mathrm{O}$ ) pointing into the interior, a series of so-called flexiballs was synthesized (Figure 9). ${ }^{12}$ Three glycoluril moieties (“G” in Figure 9) are attached to an aromatic ring in 1, 3, and 5position. The resulting capsules can be examined with the same mass spectrometric protocol as the softballs discussed above. It is however necessary to use slightly larger guest cations (or even better dications), because the cavity volume increased; Figure 9 shows some examples.

The formation of dimeric capsules is only observed, if the central ring bears ethyl groups at the 2, 4, and 6-positions which direct the binding sites for the hydrogen bonds to one side of the central spacer unit. The analogous benzene unsubstituted at $\mathrm{C}(2), \mathrm{C}(4)$, and $\mathrm{C}(6)$ does not form capsules, but likely hydrogen-bonded polymers. This behaviour can be understood by invoking entropic factors. The attachment of the glycoluril binding sites occurs through single bonds that can freely rotate. Upon capsule formation, this rotation must be frozen in a conformation suitable for dimerization - an entropically unfavourable process. The three ethyl groups restrict rotation around the three $\mathrm{C}_{\mathrm{ar}}-\mathrm{CH}_{2}$ bonds and thus lock the conformation of the monomer in an already useful way. With lower entropic costs, the dimer can form.

${ }^{1} \mathrm{H}-\mathrm{NMR}$ studies indicate the formation of homodimers from monomers $\mathbf{1 5}, \mathbf{1 6}$, and $\mathbf{1 7}$ as well as the heterodimer $\mathbf{1 5 \cdot 1 7}$ even without addition of a cationic guest. Apparently, 18 does not form homodimers as indicated by the broad NMR signals. Again, entropy plays its role: Through methylation of the amide groups, the conformation of the amide is not fixed anymore. Secondary amides prefer a transoid conformation much more than tertiary amides. Consequently, the conformation of $\mathbf{1 8}$ is not as well pre-organized as that of the other flexiball monomers. Upon the addition of 15, however, the NMR signals sharpen indicating the formation of $\mathbf{1 5 \cdot 1 8}$ heterodimers.

As expected from ${ }^{1} \mathrm{H}$ NMR measurements, the mass spectrometric analyses confirmed the formation of homodimeric capsules from 15, 16, and 17 with enclosed monoor dication $\left(\mathbf{1 9}^{+}\right.$and $\mathbf{2 0}^{2+}$ respectively). 
Furthermore, the formation of heterodimers [20 $\left.{ }^{2+} @ \mathbf{1 5} \cdot \mathbf{1 7}\right]$ as well as $\left[\mathbf{2 0}^{2+} @ 16 \cdot 17\right]$ in nearly statistical ratio to the corresponding homodimers could be observed. Comparing the experimental signal shapes of ions sprayed from acetone solutions of equimolar amounts of $\mathbf{1 5}$ and 17 (Figure 10a) and $\mathbf{1 6}$ and $\mathbf{1 7}$ (Figure 10b) respectively reveals a good fit with the isotope patterns for the statistical 1:2:1 ratio of homo- and heterodimers calculated from the natural isotopic abundance - even, if the resolution of the mass spectrometer does not suffice to resolve the individual isotope peaks of the dicationic dimer-guest complex.

Additionally, mass spectrometry yielded evidence for the formation of $\mathbf{1 5} \cdot \mathbf{1 8}$ hetero-dimers. The formation of a $\left[\mathbf{2 0}^{2+} @ \mathbf{1 5 \cdot 1 5}\right]$ homodimer is particularly favoured over the formation of the heterodimer $\left[\mathbf{2 0}^{2+} @ \mathbf{1 5} \cdot \mathbf{1 8}\right]$. As already anticipated by the NMR experiments, nearly no signal for the $\left[\mathbf{2 0}^{2+} @ \mathbf{1 8} \cdot 18\right]$ homodimer could be observed. Thus, the mass spectrometric experiments yield complementary data as compared to the NMR spectroscopic findings. While encapsulation can be analyzed by both, mass spectrometry offers the necessary tool to easily identify heterodimers by their weight. NMR spectra of heterodimers are usually much more difficult to interpret, because all species are not only present simultaneously, but also exchange guests and monomers on different time scales.

\section{The Bigball: Second-Sphere Encapsu- lation}

Attachment of four glycoluril moieties 21 to calixarene $\mathbf{2 2}$ or resorcinarene cavitand $24^{13}$ yields monomers 23 and 25 (Figure 11). Dimeric capsules from monomer $\mathbf{2 5}$, the so called "bigballs", are able to encapsulate much larger guests than the softballs described above due to their three to five times larger cavity of about $950 \AA^{3}$. The guests for ion labelling in this case, were chosen to be cryptate complexes of different alkaline and alkaline earth metals $\left(\mathbf{1 2}^{+}\right.$, $\left.13^{2+}, 14^{2+}\right)$. Other spacious dications are also possible guests, but the cryptates are particularly interesting, because their encapsulation generates Matroshka-doll-like molecule-in-molecule-in-molecule assemblies - the second sphere of encapsulation. As expected from ${ }^{1} \mathrm{H}$ NMR measurements, which show significant downfield shifts for the signals of the $\mathrm{N}-\mathrm{H}$ protons forming the seam of hydrogen bonds as well as for the signals for the $\mathrm{CH}_{2}$ protons of the encapsulated cryptate, the ESI mass spectra of solutions of $\mathbf{2 5}$ and the corresponding salt of $\mathbf{1 3}^{2+}$ or $\mathbf{1 4}^{2+}$ (with counterions $\mathrm{Cl}^{-}, \mathrm{SCN}^{-}$, $\mathrm{B}(p-\mathrm{ClPh})_{4}$ or $\left.\mathrm{ClO}_{4}^{-}\right)$showed base peaks corresponding to the cryptate dication encapsulated in the capsule dimer. ${ }^{14}$

Two aspects are interesting: a) Entropic factors again govern capsule formation. On the cavitand scaffold realized in $\mathbf{2 5}$, all four glycoluril binding sites converge to the same side of the molecule. The monomers are thus well pre-organized. If one uses a calixarene scaffold as in $\mathbf{2 3}$ with its conformational freedom to interchange between cone, 1,2-alternate, or 1,3alternate conformations, no preference for dimerization over polymerization is found. NMR spectra with broad peaks indicate that capsules are not specifically formed. 
(b) Seemingly, ion pairs are encapsulated in the bigballs, when the counterion is small enough, as e.g. for $\mathrm{SCN}^{-}$. This is indicated by the fact that the dication intensity for the dimer-guest complexes increases at the expense of a singly charged dimer-guest-anion assembly, in which the anion compensates one charge, when the ions are collided with a collision gas in the ion source. Harsher ionization conditions thus lead to the expulsion of the ion from the cavity, while the cation remains trapped due to its much larger size.

\section{Tetraurea Calixarenes: Large Assem- blies through Tethering}

So far, all capsules were formed through hydrogen bonding involving glycoluril moieties. However, other hydrogen bonding patterns are also possible. For example urea units can be used as in tetraurea calixarene capsules shown in Figure 13. ${ }^{15}$ Mass spectrometric experiments with guest cation pairs competing for the capsule result in the ranking shown. ${ }^{16}$ Tetraethyl ammonium is the best guest cation found and it fills ca. $78 \%$ of the cavity volume. This value deviates significantly from the usual $55 \%$ suggested in the literature, ${ }^{17}$ but a crystal structure of this guest cation encapsulated in the tetraurea calixarene dimer exists and provides unambiguous evidence that this degree of space filling is possible. A rationalization may come from cation- $\pi$ interactions again. The electrostatic potential energy surface of the cavity shows that the concave surface bears a substantial negative partial charge due to the entangled $\pi$-systems of the aromatic rings. ${ }^{18}$ Consequently, the cavity provides optimal conditions to accomodate a cationic guest. $^{19}$

Another new aspect comes from capsules formed from tethered monomers (Figure 14). ${ }^{16}$ If the upper rims of the calixarenes are connected through a flexible tether, the addition of a suitable guest leads to intramolecular capsule formation. If however, the tether is rigid and connects the bottom rims, intramolecular capsule formation is impossible. Either these compounds form hydrogen-bonded polymers, or the addition of suitable monomeric caps breaks the oligomeric assemblies and dumbbellor star-shaped capsule dimers and trimers can be observed. Mass spectrometry again permits to observe these ions.

\section{Dimeric Resorcinarene Capsules: The Reliability of Electrospray Ionization}

All capsules discussed so far were studied in the gas phase by mass spectrometry and in solution by NMR experiments. For all of them, both methods yield complementary results and it is clear that encapsulation of the cations also occurs in non-competitive solvents. ESI mass spectrometry thus proved to be a reliable and powerful tool to detect capsule formation.

A study of resorcinarene capsules, ${ }^{20}$ however, for the first time gave rise to inconsistencies. ${ }^{21}$ Figure 16 shows results from different states of aggregation: In the solid state, dimeric capsules are held together by a seam of hydrogen bonds mediated and extended by solvent molecules. These capsules bind quaternary ammonium ions inside their cavity. The counterions can be involved in the seam of hydrogen bonding. A computer model predicts that dimers 
would also be able to form around a tetramethyl ammonium ion without solvent molecules incorporated in the seam of hydrogen bonds. In methanol solution, however, a Job plot clearly indicates that 1:1 complexes of resorcinarene and $\mathbf{3 0}^{+}$cations prevail. Nevertheless, if that solution is diluted to $50 \mu \mathrm{M}$ concentration suitable for electrospray ionization and sprayed into the ESI ion source, the mass spectra exhibit strong signals for 2:1 complexes of host monomers and guest cation. Using equimolar mixtures of two of the resorcinarenes $\mathbf{2 6}$ - 28 resulted in the formation of heterodimers 30 $@$ 26·27, 30 ${ }^{+} @ \mathbf{2 6} \cdot 28$ and $\mathbf{3 0}^{+} @ \mathbf{2 7 \cdot 2 8}$ in nearly statistical 1:2:1 ratio relative to the corresponding homodimers. Furthermore, size selectivity studies and collision experiments suggest that the dimer-guest complexes are capsules even in the gas phase.

From these experiments, the question arises why the mass spectra do not provide a reliable picture of the solution-phase processes. Why do we see capsules in the gas phase, where there are no capsules in solution before the ionization? An answer to that question will be attempted below in the context of hexameric pyrogallarene capsules. This finding, however, immediately leads to the conclusion that one should be careful when interpreting the ESI mass spectra. Even such soft ionization methods as ESI do not necessarily provide a true picture of the solution phase, sometimes not even qualitatively.

\section{Pyrogallarene Hexamers: Supramo- lecular Chemistry Under Conditions Violating Electroneutrality?}

Hexameric resorcinarene and pyrogallarene capsules ${ }^{22}$ have been observed in the solid state and in solution. They encapsulate several neutral as well as mono- and dicationic guests.

In order to transfer the hexameric capsules into the gas phase, we took the following approach: First, a solution of pyrogallarene 29 alone was electrosprayed (Figure 18a). The typical distribution of unspecific aggregates is seen in the mass spectrum with intensities decreasing with increasing monomer count. No specific formation of any capsule is observed. When a small guest cation such as $\mathbf{3 0}^{+}$is added, the whole series converges into one dimerguest signal (Figure 18b) indicating that the cation templates dimer formation as found for other resorcinarenes earlier (see above). Larger ammonium ions such as $\mathbf{8}^{+}$ (Figure 18c) template the formation of larger assemblies, but with the lack of specificity for a particular one. Thus, a broad distribution of different oligomers is observed.

The use of larger guest cations with a suitable pseudo-octahedral shape such as $\left[\mathrm{Ru}(\mathrm{bpy})_{3}\right]^{2+} \mathbf{3 1}^{2+}$ (bpy = 2,2'-bipyridine) leads to the nearly selective formation of hexameric resorcinarene and pyrogallarene capsules with encapsulated $\mathbf{3 1}^{2+23}$. Apparently, the formation of a hexameric capsule requires an appropriate template that exactly fits into the cavity of this capsule such as the pseudo-octahedral complex $31^{2+}$ that is congruent in shape to the interior of the hexamer.

Tetramethylated resorcinarene $\mathbf{3 2}$ may be used as a control compound. Four of its hydrogen bonding sites are blocked with methyl groups. Unspecific binding to the 
guest dication $\mathbf{3 1}^{\mathbf{2 +}}$ should still be possible, while the hexameric capsule cannot be formed as easily. In the ESI mass spectrum, 32 does not show any hexamer formation with $31^{2+}$ providing evidence for the formation of an intact capsule.

To have an even stronger proof for the retention of the capsular structure in the gas phase, mass-selected $\left[\mathbf{3 1} @ \mathbf{2 9}_{6}\right]^{2+}$ ions were irradiated with a $\mathrm{CO}_{2}$ laser in the IR region in order to investigate the fragmentation behavior. These experiments showed that liberation of the guest cation $\mathbf{3 1}{ }^{2+}$ does not proceed until dissociation of three pyrogallarene monomers has occurred. This is exactly the expected behaviour for the expected hexameric capsule with the guest inside the cavity. In turn, if the guest were attached to the outside of the capsule, one would expect the assembly to fragment through loss of the complete hexamer at least in competition to monomer losses. Consequently, the combination of suitable control experiments and gas-phase fragmentation reactions leads to the conclusion that a capsule is indeed formed.

However, a similar problem as discussed above for the resorcinarene dimer-guest complexes evolves, when one tries to find the hexamer with an encapsulated $\mathbf{3 1}^{\mathbf{2 +}}$ dication in solution by NMR methods. So far, we could not find any indication that the dication is indeed encapsulated in the same solvent mixture which were used for the ESI-MS experiments $\left(\mathrm{CHCl}_{3}\right.$ : acetone 2:1). A look at the model shown in Figure 17 makes clear that the pyridine rings dive into the cavities of the individual resorcinarenes and thus should experience the anisotropy of the aromatic rings. Thus, one would expect the guest signals to shift up- field. So, again: Why do we see specific hexameric capsules in the gas phase, when they are not present in solution?

The answer could be the following: In solution, the positive charges of the $\mathbf{3 1}^{\mathbf{2 +}}$ dications are counterbalanced by the corresponding anions. If the guest salts form ion pairs in solution, the encapsulation of the dication requires charge separation energy. If this energy is not counterbalanced by a sufficiently high binding energy of the guest inside the capsule cavity, encapsulation would not occur, thus preventing capsule formation in solution. However, upon the positive ion mode of the electrospray process, positively charged droplets are formed. Consequently, inside these droplets, an excess of free $\mathbf{3 1}{ }^{2+}$ dications is present which can effectively template the formation of the capsule, because charge separation is no longer necessary. The hexameric capsules would therefore be formed in the charged droplets and desolvation transfers them into the gas phase. If this still somewhat preliminary idea holds true, ESI mass spectrometry makes it possible to examine supramolecular chemistry which only proceeds under conditions violating electroneutrality.

Is there additional evidence for this assumption? Indeed, there is. Avram and Cohen $^{24}$ recently reported that hexameric capsules with other guests exchange monomers quite slowly. Also, pyrogallarenes and resorcinarenes self-sort and do not easily form heterohexamers. If we take solutions of two different resorcinarenes, add the guest salt $\mathbf{3 1}^{\mathbf{2 +}}\left(\mathrm{PF}_{6}{ }^{-}\right)_{2}$, mix both solutions and immediately measure a mass spectrum, a statistical distribution is observed even after half a minute. The same 
experiment conducted with a pyrogallarene and a resorcinarene again leads to a nearstatistical mixture of all possible homoand heterohexamers. Quite obviously, this behaviour is in marked contrast to the observations by Avram and Cohen. It can, however, be easily rationalized by the charged-droplet idea: The time during which the hexamer ions can form in the droplets is in the range of microseconds. Consequently, no equilibrium can be reached. If the hexamers do not form in solution before mixing, both solutions contain only monomers, which during the short time of the ESI process lead to a statistical distribution of all possible hexamers. The self-sorting of pyrogallarenes and resorcinarenes cannot be observed, since first any hexamers are formed far from equilibrium. The reaction time in the droplets is too short to allow for a self-sorting to take place.

\section{Conclusions}

Mass spectrometry is a powerful method for the investigation of non-covalently bound supramolecular complexes. It allows us to separate the species under study from environmental influences, so that only the intrinsic properties of the corresponding aggregates are observed. A method was established which provides a means to unambiguously characterize hydrogen bonded capsules in the gas phase. However, it is necessary to take into account the particularities of the ionization method. Under particular circumstances, ESI may be misleading, when interpreted carelessly. The seeming disadvantage can however be converted into an advantage, if one consid- ers that a mass spectrometer cannot only be a detector for solution-phase processes or a laboratory to study gas-phase reactions. During the ESI process, charged droplets are formed in which electroneutrality is violated. Chemistry, which only occurs under these conditions can be examined by ESI mass spectrometry, if it is known exactly, what is going on in solution (e.g. through NMR experiments) and what occurs in the gas phase (e.g. through tandem MS experiments). Chemistry different from both may be due to reactions in the charged droplets and may only occur, if electroneutrality is violated.

\section{References}

(a) M. M. Conn, J. Rebek Jr., Chem. Rev., 97, 1647-1668 (1997); (b) C. A. Schalley, $A d v$. Mater., 11, 1535-1537 (1999); (c) C. A. Schalley, J. Rebek, Jr. in: Stimulating Concepts in Chemistry, F. Vögtle, J. F. Stoddart, M. Shibasaki (Eds.), p. 199-210, Wiley-VCH, Weinheim (2000); (d) F. Hof, S. L. Craig, C. Nuckolls, J. Rebek, Jr., Angew. Chem., 114, 15561578 (2002); Angew. Chem. Int. Ed., 41, 14881508 (2002)

2 (a) C. A. Schalley, Int. J. Mass Spectrom., 194, 11-39 (2000); (b) C. A. Schalley, Mass Spectrom. Rev., 20, 253-309 (2001); (c) B. Baytekin, H. T. Baytekin, C. A. Schalley, Org. Biomol. Chem., 4, 2825-2841 (2006)

The gas phase experiments discussed in this review were performed using different ESI and ESI mass spectrometers with either TOF or FTICR detetor. For experimental details, see the references cited herein. For reviews on Electrospray Ionisation and Ion Cyclotron Resonance mass spectrometry, see for example: (a) S. J. Gaskell, J. Mass Spectrom., 32, 677-688 (1997); (b) A. G. Marshall, C. L. 
Hendrickson, G. S. Jackson, Mass Spectrom. Rev., 17, 1-35 (1998).

4 R. Meissner, X. Garcías, S. Mecozzi, J. Rebek, Jr., J. Am. Chem. Soc., 119, 77-85 (1997)

5 J. Kang, G. Hilmerson, J. Rebek, Jr., J. Am. Chem. Soc., 120, 3650-3656 (1998)

6 J. M. Rivera, T. Martín, J. Rebek, Jr., J. Am. Chem. Soc., 120, 819-820 (1998)

7 J. Kang, J. Rebek, Jr., Chem. Soc. Rev., 255264 (1996)

8 R. Meissner, J. De Mendoza, J. Rebek, Jr., Science, 270, 1485-1488 (1995)

9 C. A. Schalley, J. M. Rivera, T. Martín, J. Santamaría, G. Siuzdak, J. Rebek, Jr., Eur. J. Org. Chem., 1325-1331 (1999)

10 C.A. Schalley, T. Martín, U. Obst, J. Rebek, Jr., J. Am. Chem. Soc., 121, 2133-2138 (1999)

11 Ma, J. C.; Dougherty, D. A. Chem. Rev., 97, 1303-1324 (1997)

12 B. M. O’Leary, T. Szabo, N. Svenstrup, C. A. Schalley, A. Lützen, M. Schäfer, J. Rebek, Jr., J. Am. Chem. Soc., 123, 11519-11533 (2001)

13 J. C. Sherman, C. B. Knobler, D. J. Cram, J. Am. Chem. Soc., 113, 2194-2204 (1991)

14 A. Lützen, A. R. Renslo, C. A. Schalley, B. M. O’Leary, J. Rebek, Jr., J. Am. Chem. Soc., 121, 7455-7456 (1999)

15 (a) K. D. Shimizu, J. Rebek, Jr. Proc. Natl. Acad. Sci. USA, 92, 12403-12407 (1995). (b) O. Mogck, V. Böhmer, W. Vogt, Tetrahedron, 52, 8489-8496 (1996)

16 (a) C. A. Schalley, R. K. Castellano, M. S. Brody, D. M. Rudkevich, G. Siuzdak, J. Rebek, Jr., J. Am. Chem Soc., 121, 4568-4579 (1999);

(b) M. S. Brody, C. A. Schalley, D. M. Rudkevich, J. Rebek, Jr., Angew. Chem., 111, 1738-1742 (1999); Angew. Chem. Int. Ed., 38, 1640-1644 (1999)

17 S. Mecozzi, J. Rebek, Jr., Chem. Eur. J., 4, 1016-1022 (1998)
M. Kamieth, F.-G. Klärner, J. F. Diederich, Angew. Chem., 110, 3497-3500 (1998); Angew. Chem. Int. Ed. Engl., 45, 3303-3306 (1998) (a) L. Frish, M. O.Vysotsky, S. E. Matthews, V. Böhmer, Y. Cohen, J. Chem. Soc., Perkin. Trans. 2, 88-93 (2002); (b) L. Frish, M. O.Vysotsky, V. Böhmer, Y. Cohen, Org. Biomol. Chem., 1, 2011-2014 (2003) (a) K. Murayama, K. Aoki, Chem. Commun., 607-608 (1998); (b) A. Shivanyuk, K. Rissanen, E. Kolehmainen, Chem. Commun., 11071108 (2000); (c) A. Shivanyuk, J. Rebek, Jr., Chem. Commun., 2374-2375 (2001); (d) H. Mansikkamäki, M. Nissinen, K. Rissanen, Chem. Commun., 1902-1903 (2002)

21 H. Mansikkamäki, C. A. Schalley, M. Nissinen, K. Rissanen, New J. Chem., 27, 88-97 (2003); H. Mansikkamäki, C. A. Schalley, M. Nissinen, K. Rissanen, New J. Chem., 29, 116-127 (2005) (a) L. R. MacGillvray and J. L. Atwood, Nature, 389, 469-472 (1997); (b) T. Gerkensmeier, W. Iwanek, C. Agena, R. Fröhlich, S. Kotila, C. Näther, J. Mattay, Eur. J. Org. Chem., 2257-2265 (1999); (c) A. Shivanyuk, J. Rebek, Jr., Chem. Commun., 2424-2425 (2001); (d) A. Shivanyuk, J. Rebek, Jr., Proc. Natl. Acad. Sci. USA, 98, 7662-7665 (2001); e) L. Avram, Y. Cohen, J. Am. Chem. Soc., 124, 15148-15149 (2002); f) L. Avram, Y. Cohen, Org. Lett., 5, 3329-3332 (2003).

23 N. K. Beyeh, M. Kogej, A. Åhman, K. Rissanen, C. A. Schalley, Angew. Chem., 118, 5339-5342 (2006); Angew. Chem. Int. Ed. Engl., 45, 5214-5218 (2006)

24 L. Avram, Y. Cohen, J. Am. Chem. Soc., 126, 11556-11563 (2004) 


\section{Figure Captions}

Figure 1. Self-complementary building blocks of the molecular softballs and different guest cations. Monomer 5 bears methyl-blocked binding sites and thus serves as a control compound which does not form dimeric capsules.

Figure 2. Force-field-optimized geometries of the dimeric capsules $\mathbf{1 \cdot 1} \mathbf{- 4 \cdot 4}$; solubilizing R groups and carbon-bound hydrogen atoms are omitted for clarity.

Figure 3. ESI mass spectra of $50 \mu \mathrm{M}$ chloroform solutions of softballs $\mathbf{1 \bullet 1} \mathbf{- 4 \cdot 4}$ with 1 eq. of guest cation $\mathbf{6 a}^{+}$.

Figure 4. S-shaped monomer for control experiments. Due to the inappropriate preorganization of the two glycoluril units, no dimer formation can occur.

Figure 5. Electrospray mass spectra of chloroform solutions of $\mathbf{3 \cdot 3}$ and $\mathbf{4 \cdot 4}$ with $6 \mathbf{a}^{+} \mathrm{BF}_{4}^{-}$as the guest salt.

Figure 6. Collision-induced covalent bond cleavages which can compete with monomer loss and guest expulsion in the gas phase.

Figure 7. Tetrameric capsules (inset) and the ESI mass spectrum obtained from a $50 \mu \mathrm{M}$ chloroform solution of monomer 9 and guest salt $\mathbf{6 a}^{+} \mathrm{BF}_{4}^{-}$. Note that the high intensity of the tetramer-guest complex alone already indicates the formation of a specific assembly.

Figure 8. Comparison between neutral and cationic guests of identical sizes and shapes lead to the conclusion that cation-p interactions are pivotal for guest binding in the tetrameric capsules.

Figure 9. Flexiball monomers and guest (di)cations for the flexiballs and bigballs (see below), with which a mass spectrometric characterization becomes possible.

Figure 11. Modular synthesis of cavitand-based capsule monomers 23 and 25.

Figure 12. Computer model of the bigball (top left), dicationic guests (top) and ESI mass spectrum of the dimer-cryptate guest.

Figure 13. Tetraurea calixarene monomer (bottom right), computer model of the dimeric capsule (bottom left). Typical guest cations (top right) and electrostatic potential energy surface of the capsule interior (top left). Percentages are packing coefficients of the guest inside the cavity; numbers below show guest selectivities as obtained from competition experiments with guest pairs.

Figure 14. Larger assemblies through tethering of monomers: A flexible linker between the upper rims provides an intramolecularly closing capsule, rigid tethers at the bottom rims lead to dumbbell- and star-shaped capsule dimers and trimers when a suitable cap is provided.

Figure 15. Resorcinarenes and pyrogallarenes that were tested for capsule formation. 
Figure 16. Top right: Crystal structure of a solvent-mediated dimeric capsule formed from tetramethyl ammonium $\left(\mathbf{3 0}^{+}\right)$and two resorcinarenes. Top left: Dimer-guest complex with $\mathbf{3 0}^{+}$ as calculated with the Amber* force field (no solvent molecules in the hydrogen bonding seam). Center: Job plot indicating 1:1 complex fomration in methanol. Bottom: ESI mass spectra of methanol solutions of resorcinarenes $\mathbf{2 6 - 2 8}$ with $\mathbf{3 0}^{+}$as the guest cation.

Figure 17. Computer-generated structure of the pyrogallarene hexamer with encapsulated pseudo-octahedral bpy ${ }_{3} \mathrm{Ru}(\mathrm{II})$ dications.

Figure 18. ESI-FTICR mass spectra of a) a $200 \mu \mathrm{M} \mathrm{CHCl}_{3}$ : acetone $(2: 1)$ solution of 29, b) after addition of $\mathbf{3 0}^{+} \mathrm{BF}_{4}^{-}$or c) $\left(\mathbf{8}^{+}\right)_{3}\left[\mathrm{Fe}(\mathrm{CN})_{6}\right]^{3-}$. d,e) ESI-FTICR mass spectra of the same solution of $\mathbf{2 9}$ and $\mathbf{2 7}$, respectively, with $\mathbf{3 1}^{\mathbf{2 +}}\left(\mathrm{PF}_{6}^{-}\right)_{2}$ optimized for hexamer intensity. f) Control experiment with tetramethyl resorcinarene 32. Insets: Experimental and calculated isotope patterns of the hexamer ions $\left[\mathbf{3 1} @ \mathbf{2 9}_{6}\right]^{2+}$ and $\left[\mathbf{3 1} @ \mathbf{2 7}_{6}\right]^{2+}$.

Figure 19. Infrared Multiphoton Dissociation (IRMPD) experiment with mass-selected $[31 @ 296]^{2+}$. Increasing irradiation times lead to consecutive monomer losses. The formation of bare $\mathbf{3 1}^{2+}$ starts to compete with the loss of additional monomers from the trimer $\left[31 @ 29_{3}\right]^{2+}$. 


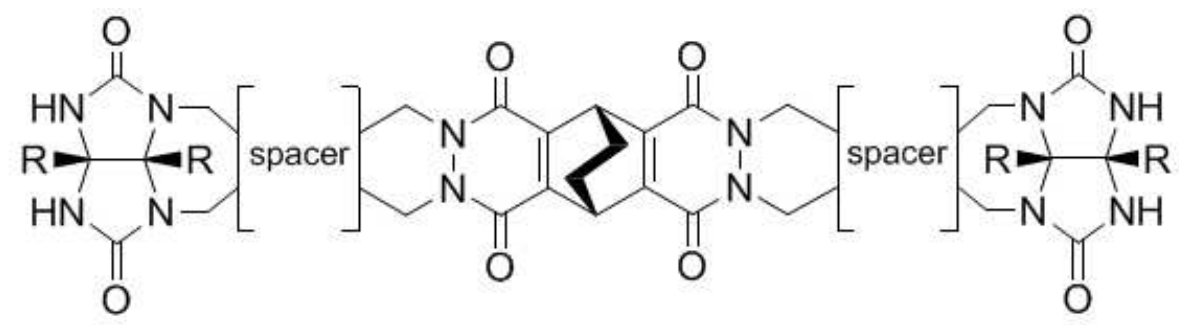

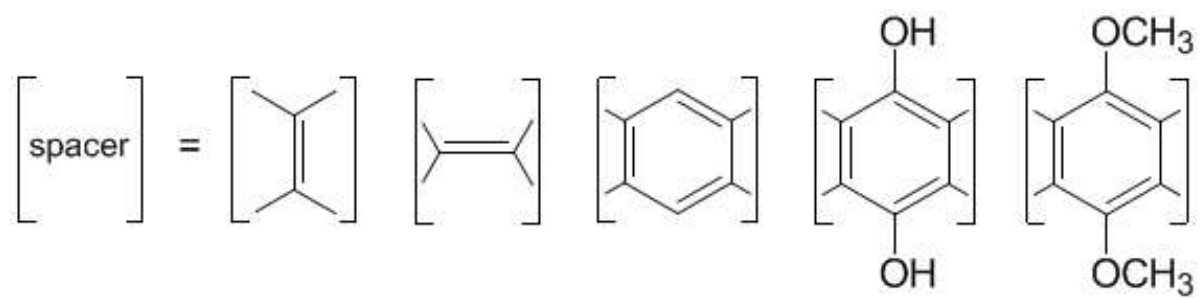

1

2

3

4

5
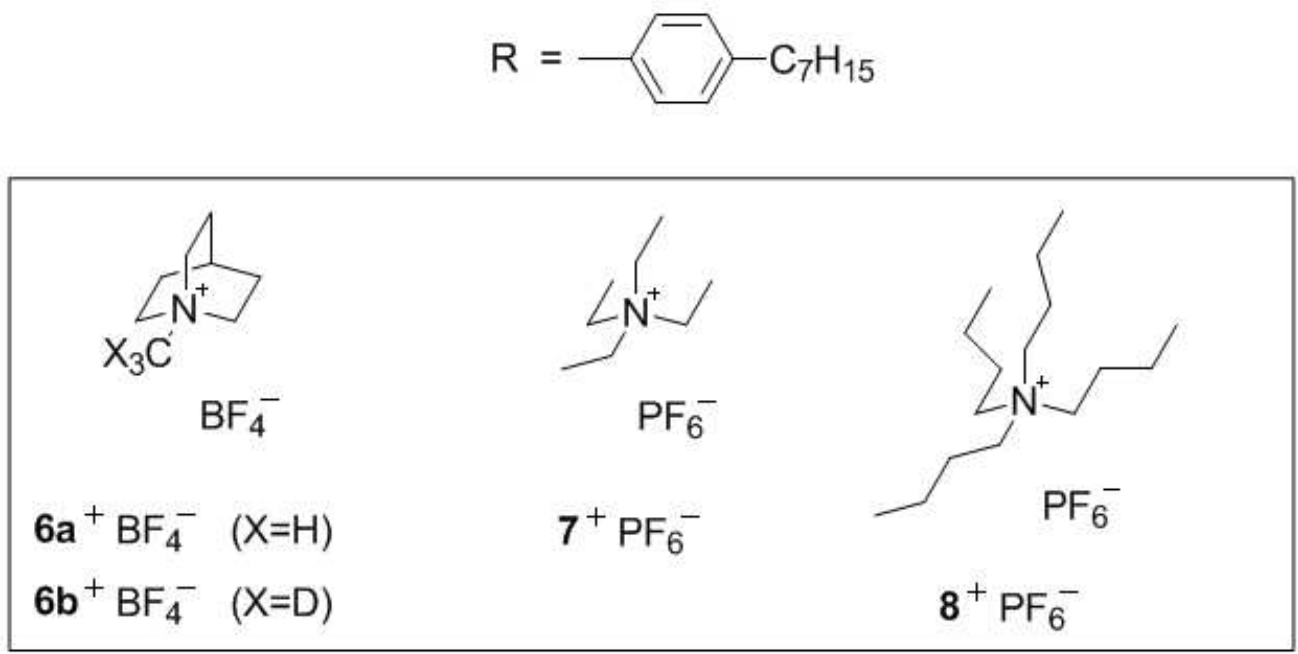

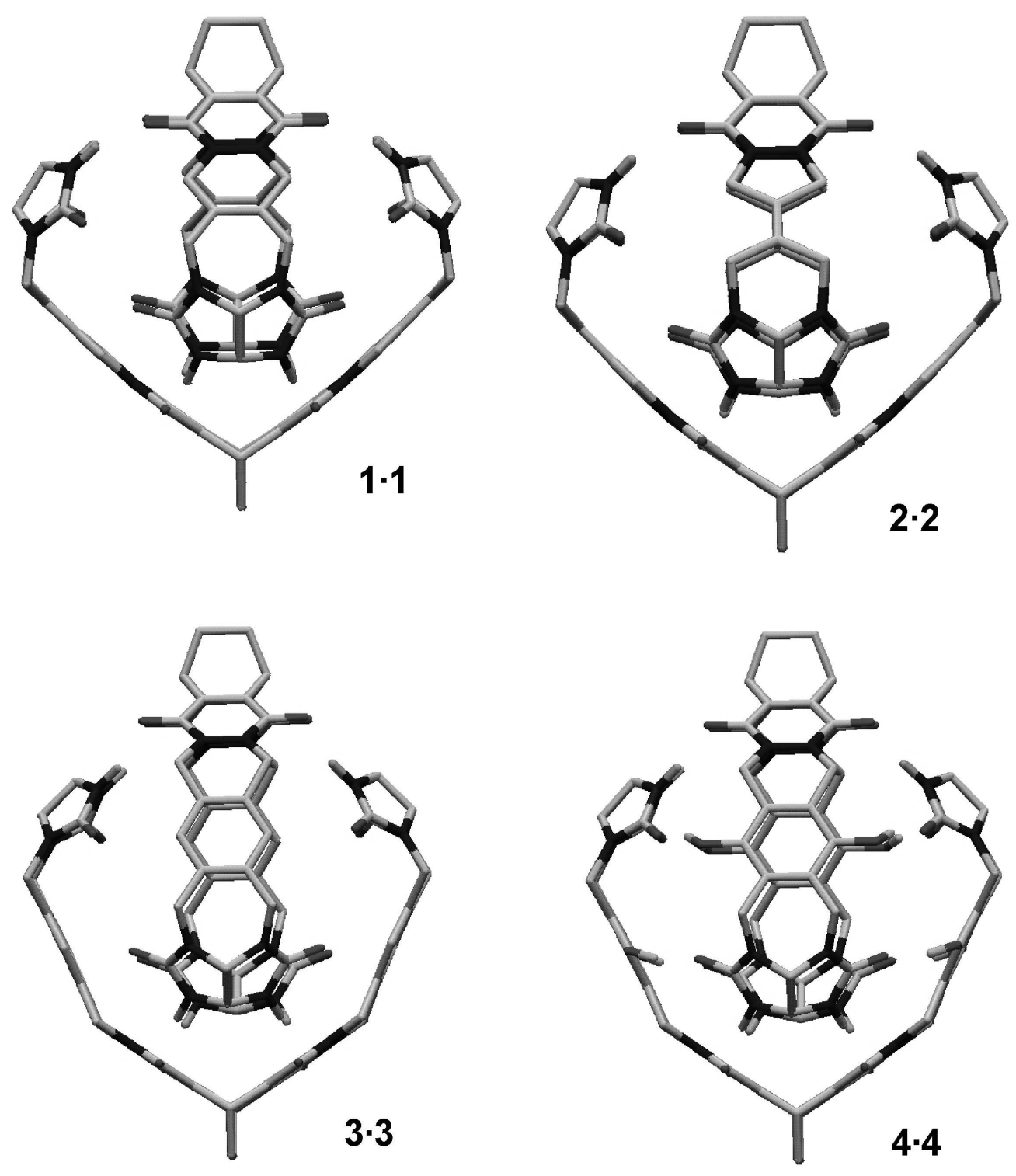

$197 \times 227 \mathrm{~mm}(299 \times 299$ DPI $)$ 
(a)

\section{[6a+@1·1]}

$\left[6 \mathrm{a}^{+} \cdot 1\right]$ $\mathrm{m} / \mathrm{z}=1533$

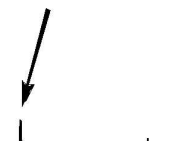

$\mathrm{m} / \mathrm{z}=2939$

\section{$\left[\mathrm{CHCl}_{3} @ 1 \cdot 1\right] \mathrm{Na}^{+}$}

$\mathrm{m} / \mathrm{z}=2954$

(b)

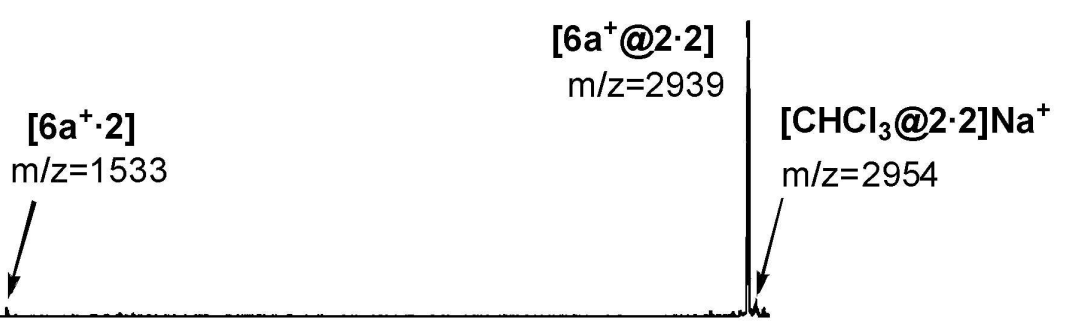

(C) $\begin{gathered}{\left[6 \mathrm{a}^{+} \cdot 3\right]} \\ \mathrm{m} / \mathrm{z}=1633\end{gathered}$

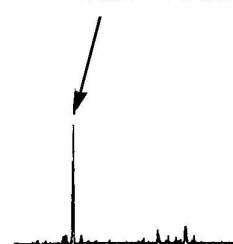

$\left[\mathrm{CHCl}_{3} @ 3 \cdot 3\right] \mathrm{Na}^{+}$ $\mathrm{m} / \mathrm{z}=3155$

(d)

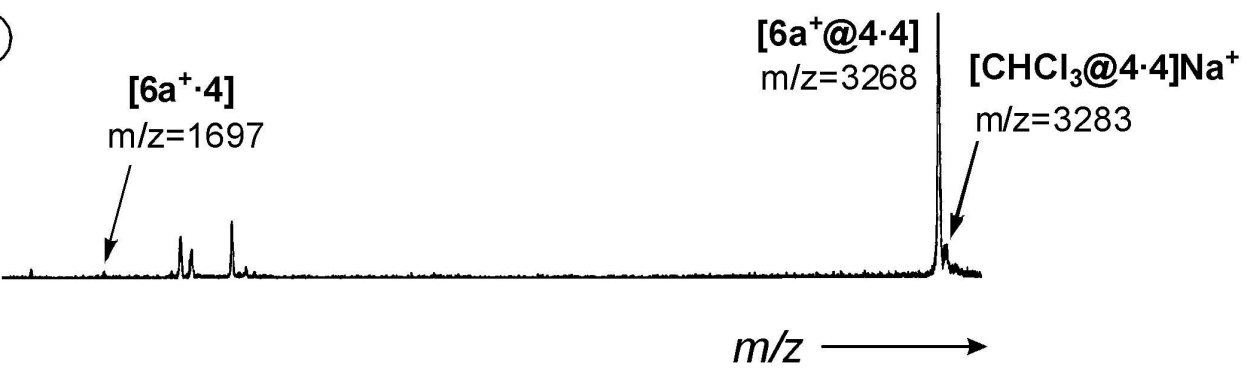

$184 \times 218 \mathrm{~mm}(300 \times 300 \mathrm{DPI})$ 


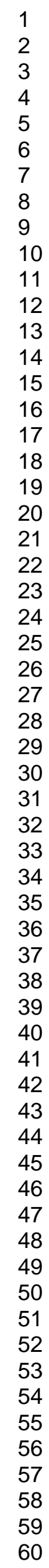

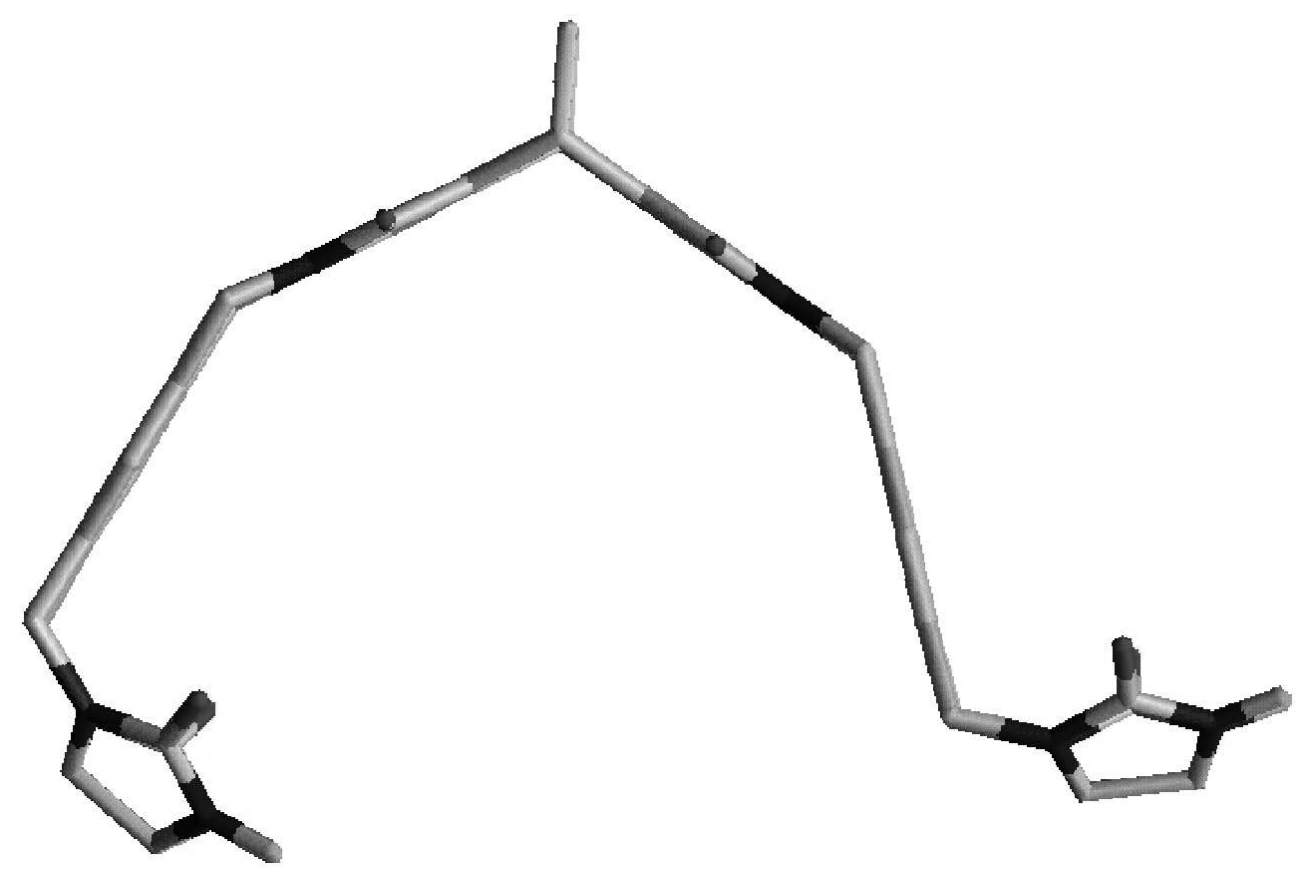

$110 \times 75 \mathrm{~mm}(299 \times 299$ DPI $)$ 


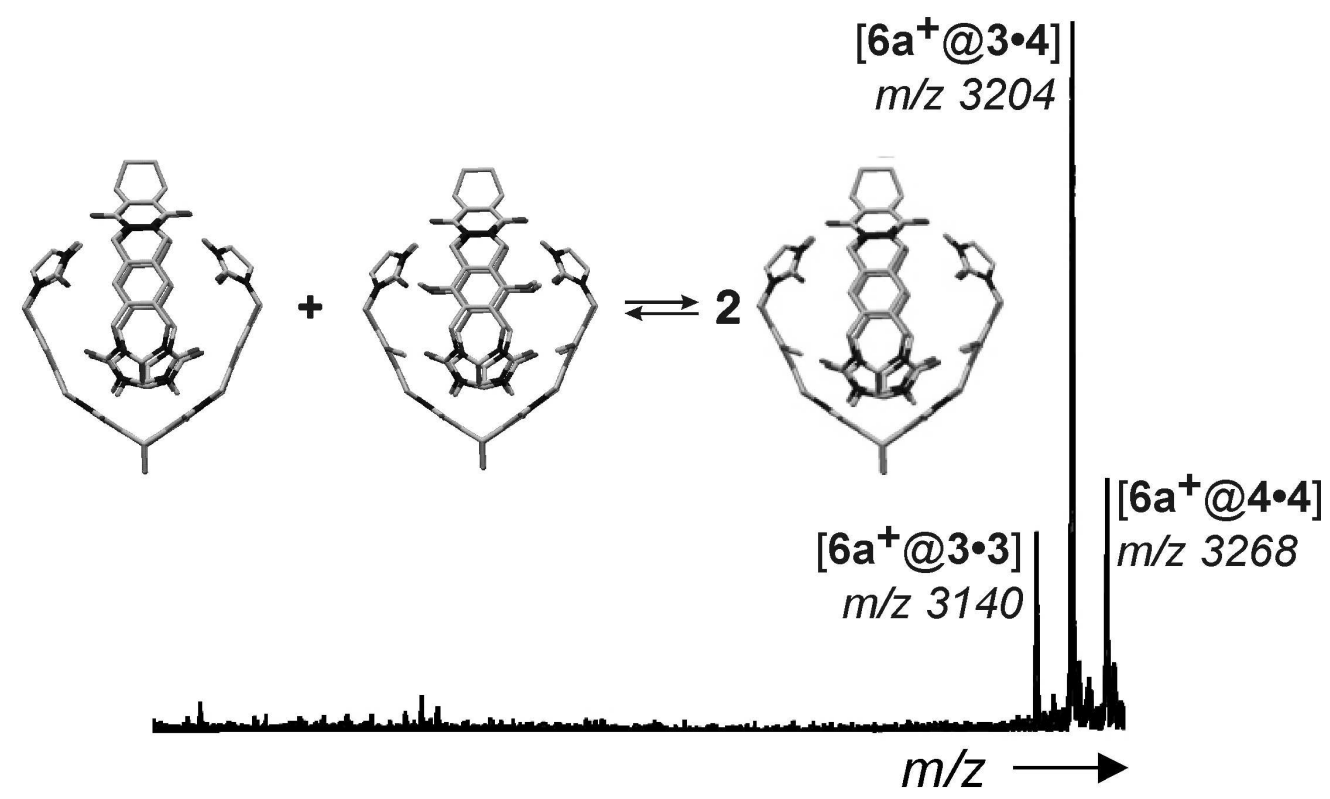

$188 \times 118 \mathrm{~mm}(299 \times 299$ DPI $)$ 


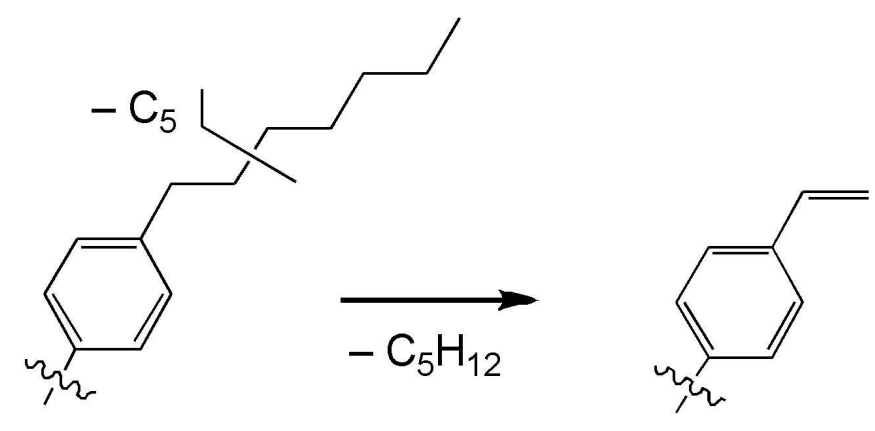

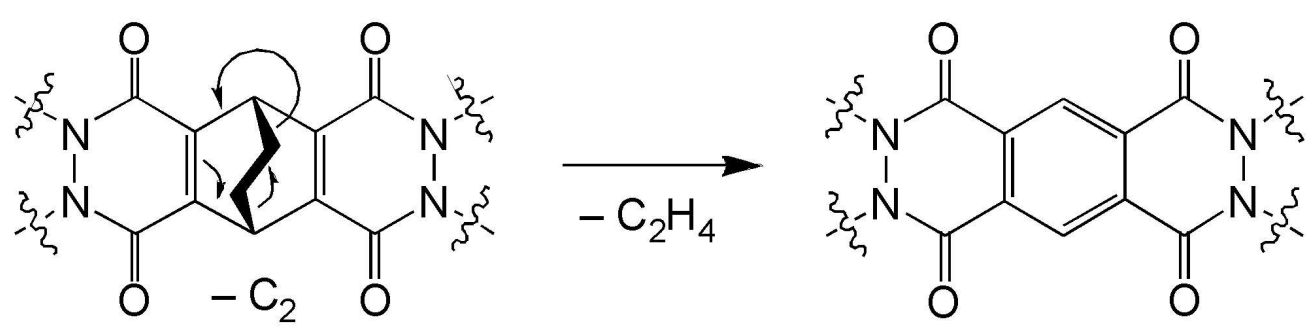

$168 \times 107 \mathrm{~mm}(300 \times 300 \mathrm{DPI})$ 


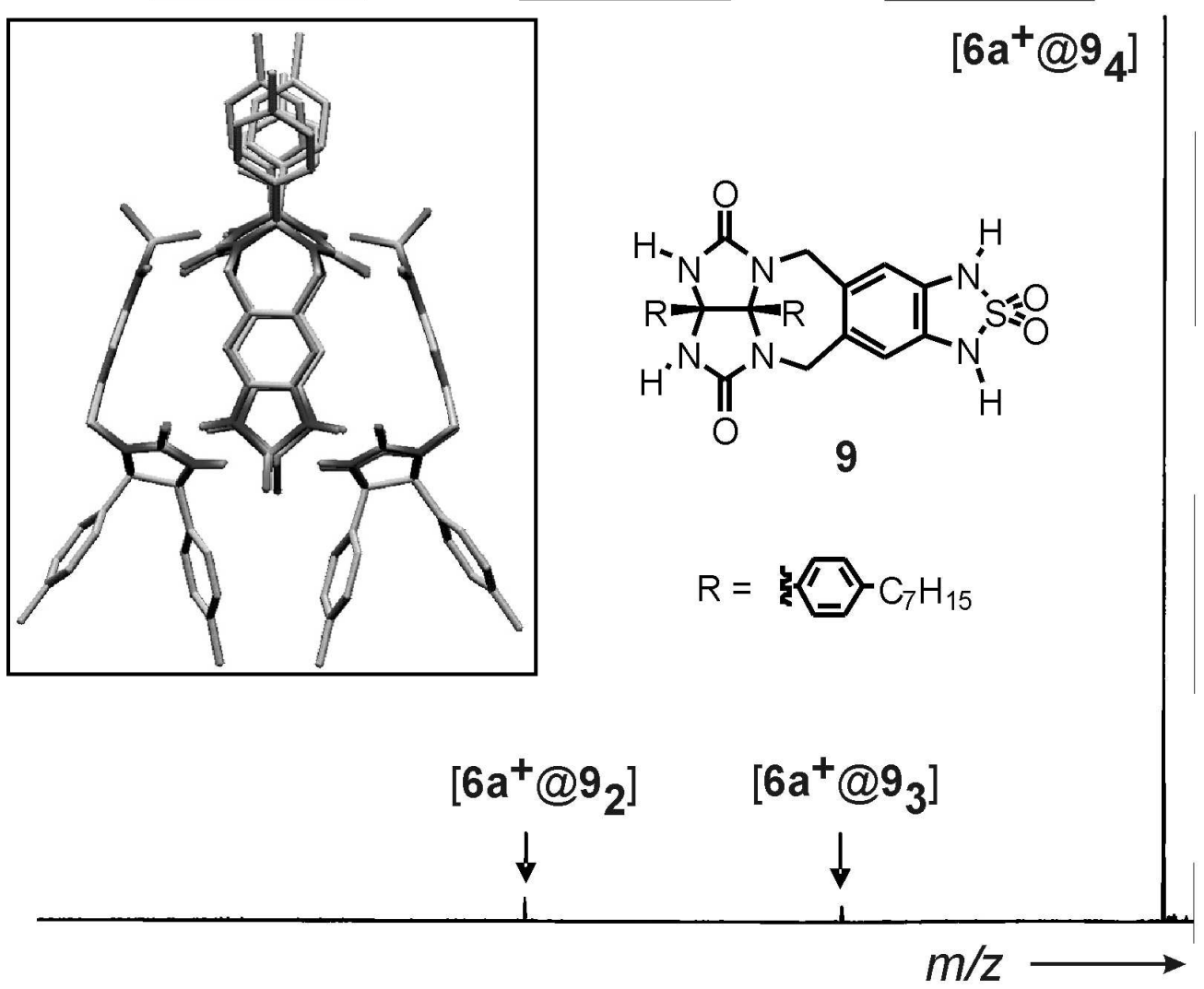

$137 \times 114 \mathrm{~mm}(299 \times 299 \mathrm{DPI})$ 
<smiles>CCc1c(CNC(=O)Cl)c(CC)c(CNC(=O)Cl)c(CC)c1CNC(=O)Cl</smiles><smiles>CCc1c(CC(=O)NO)c(CC)c(CC(=O)NO)c(CC)c1CC(=O)NO</smiles><smiles>CCc1c(COC(=O)O)c(CC)c(COC(=O)O)c(CC)c1COC(=O)O</smiles><smiles>CCc1c(CN(C)C(=O)O)c(CC)c(CN(C)C(=O)Cl)c(CC)c1CN(C)C(=O)O</smiles>
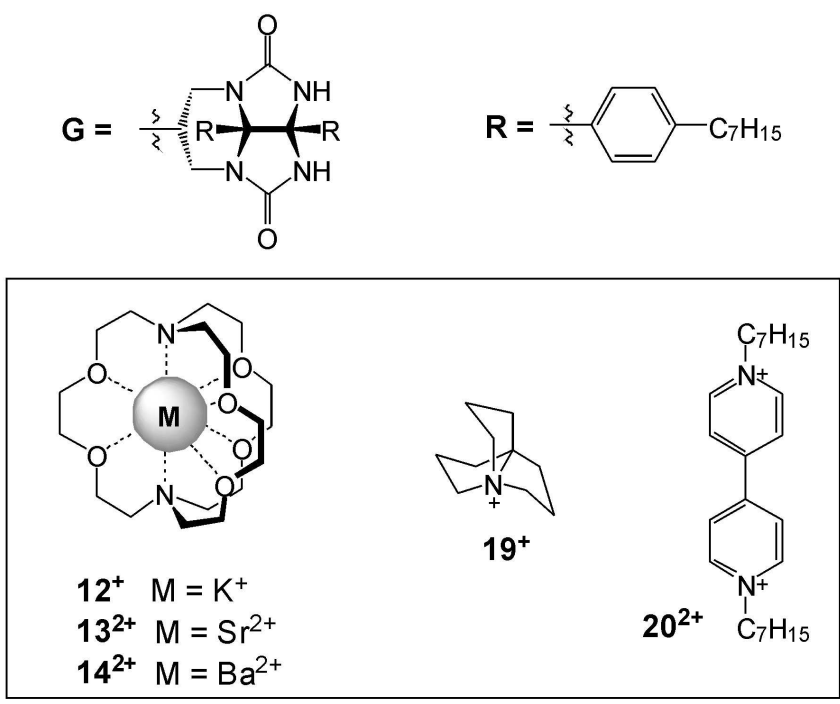

$151 \times 280 \mathrm{~mm}(299 \times 299$ DPI $)$ 


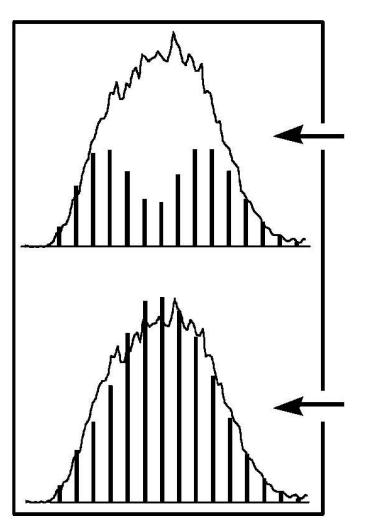

$\left[20^{2+} @ 15 \cdot 15\right]$

$\left[20^{2+} @ 15_{m} \cdot 17_{n}\right]$

$(n+m=2)$ [20 @17•17] $1: 1$

[20 $2+@ 15 \cdot 15]$

[202+@15•17]

[20 @17.17]

$1: 2: 1$
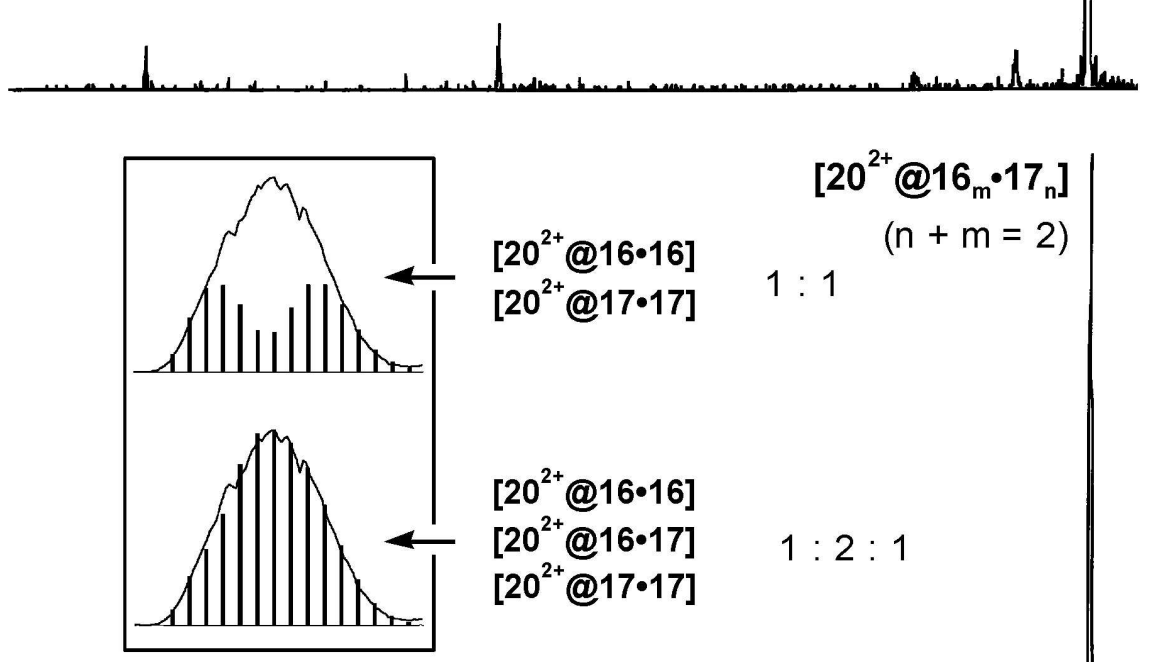

[200 @16•16]

\section{[20 $\left.0^{2+} @ 16_{m} \cdot 17_{n}\right]$} $(n+m=2)$ $\left[20^{2+} @ 17 \cdot 17\right] \quad 1: 1$

[20 $2+@ 16 \cdot 16]$

[200¹16•17]

[20 @17•17]

$1: 2: 1$

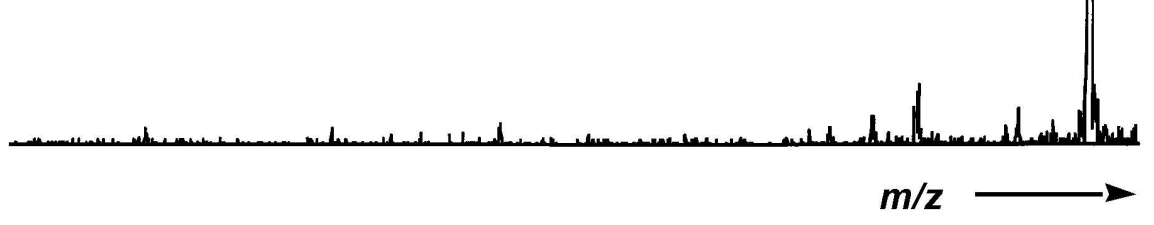

$162 \times 210 \mathrm{~mm}(300 \times 300 \mathrm{DPI})$ 


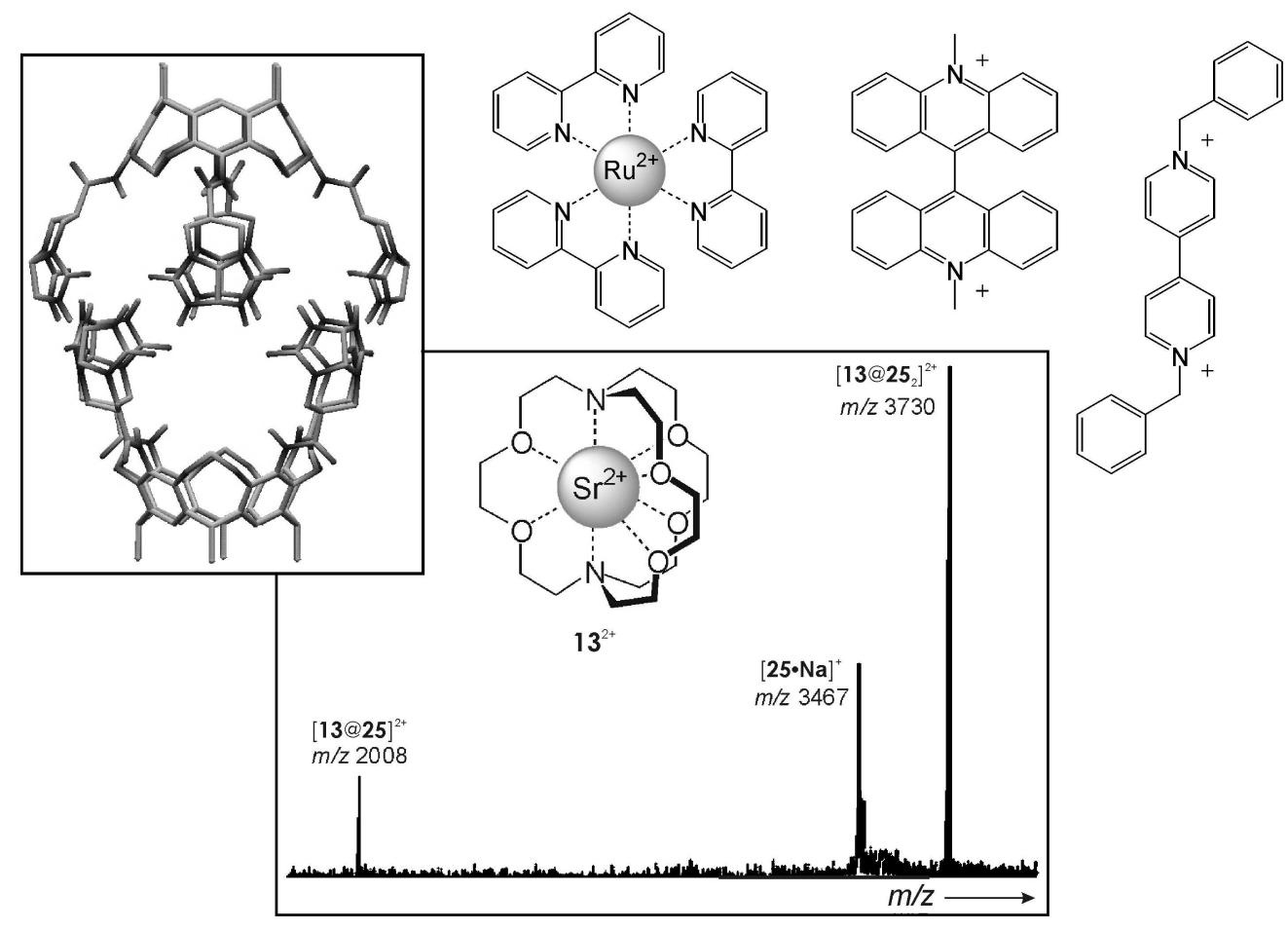

$242 \times 173 \mathrm{~mm}(299 \times 299$ DPI $)$ 


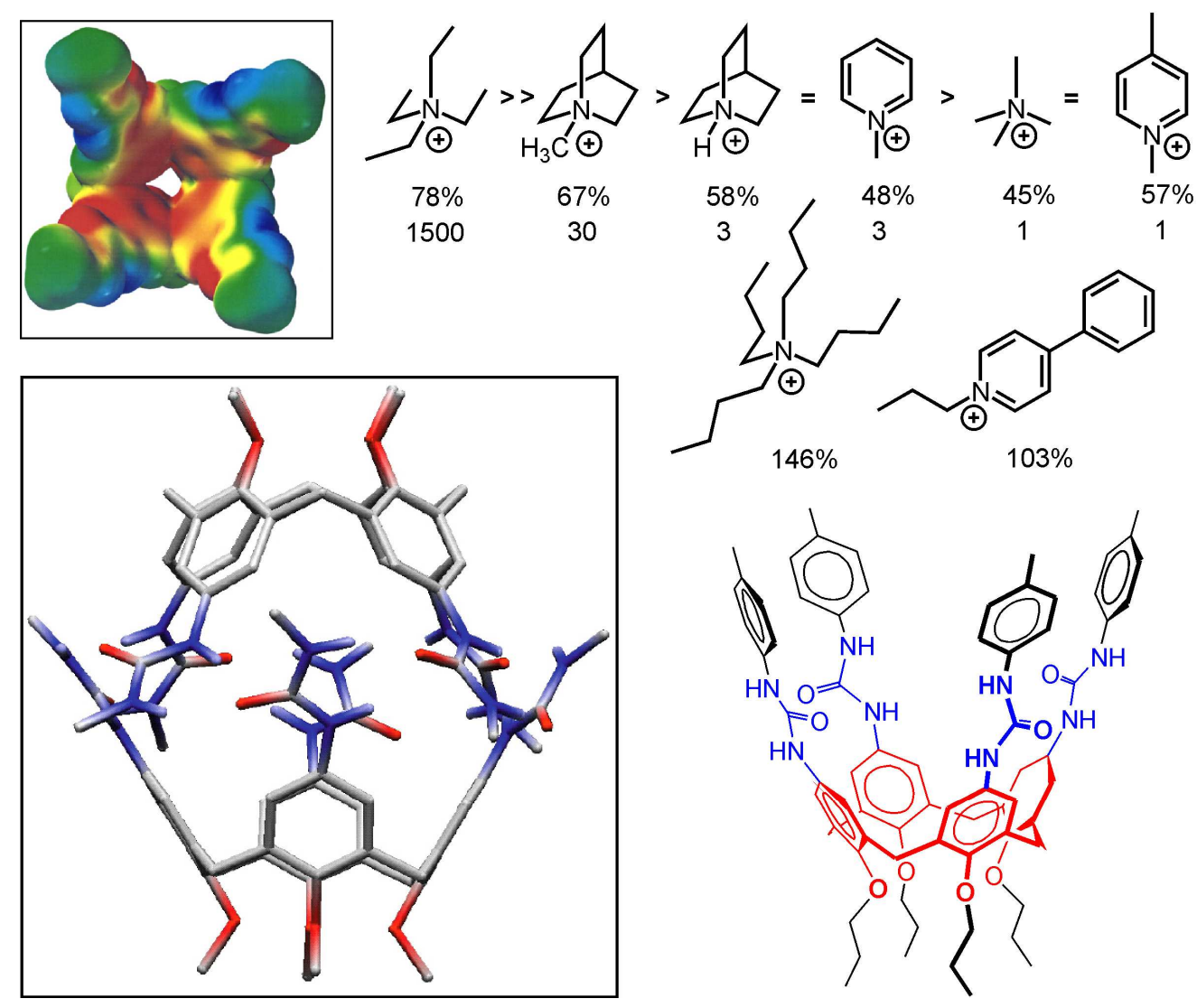

$203 \times 171 \mathrm{~mm}(299 \times 299$ DPI $)$ 


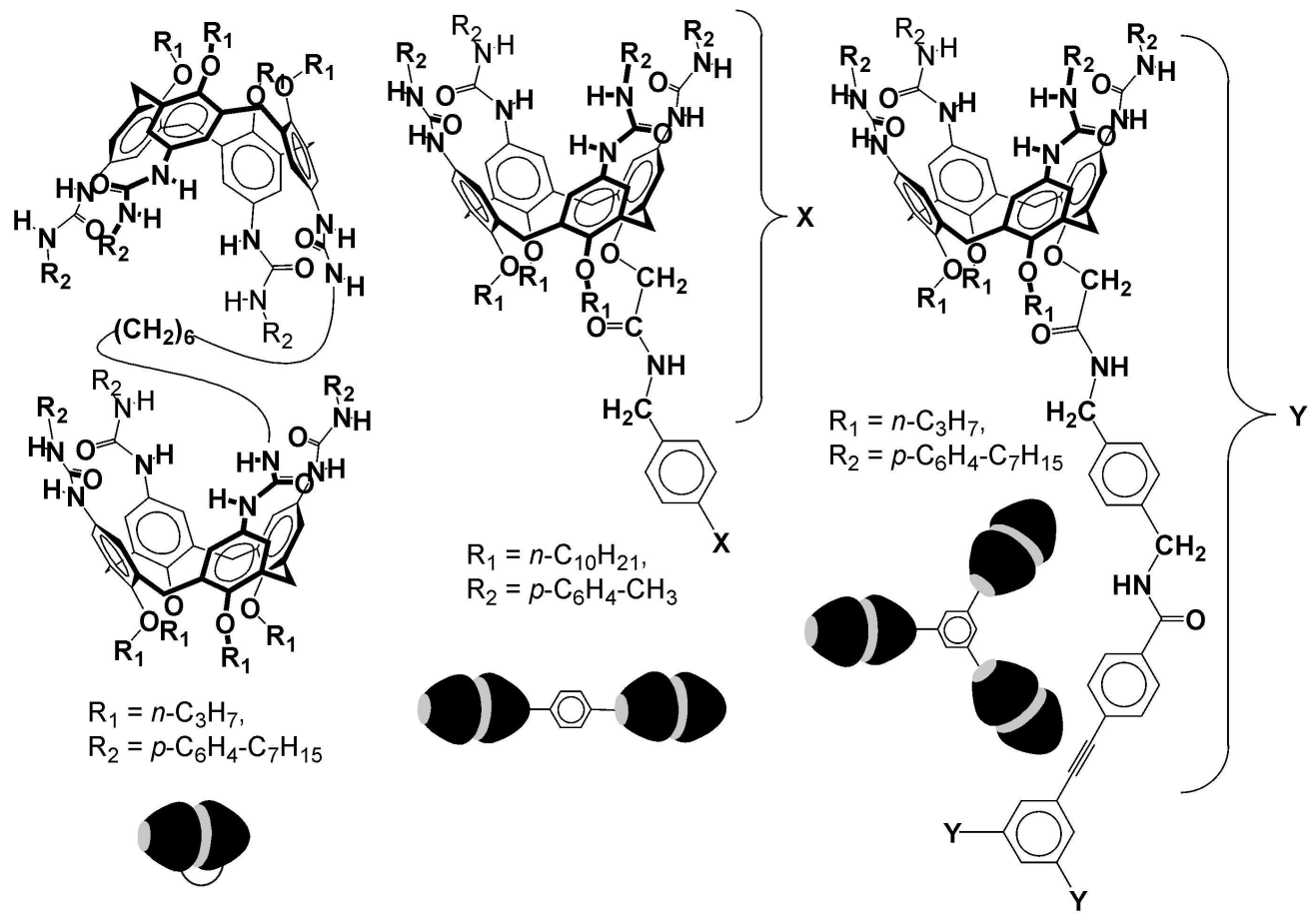

$234 \times 168 \mathrm{~mm}(299 \times 299 \mathrm{DPI})$ 


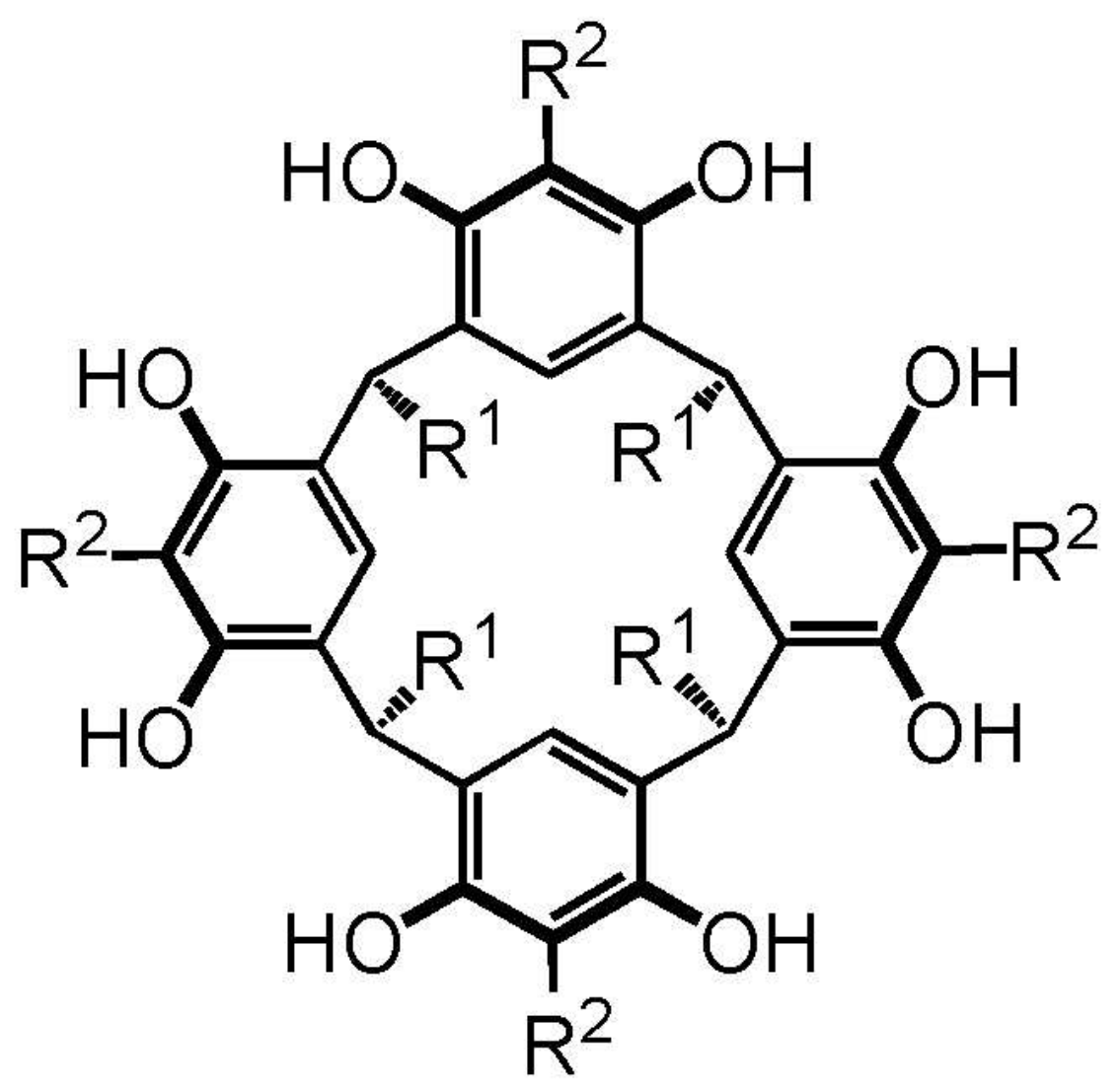

$26 \mathrm{R}^{1}=\mathrm{CH}_{3} \quad \mathrm{R}^{2}=\mathrm{H}$

$27 \mathrm{R}^{1}=\mathrm{C}_{2} \mathrm{H}_{5} \quad \mathrm{R}^{2}=\mathrm{H}$

$28 \mathrm{R}^{1}=\mathrm{C}_{3} \mathrm{H}_{7} \quad \mathrm{R}^{2}=\mathrm{H}$

$29 \mathrm{R}^{1}=\mathrm{C}_{3} \mathrm{H}_{7} \quad \mathrm{R}^{2}=\mathrm{OH}$

$56 \times 77 \mathrm{~mm}(299 \times 299$ DPI $)$ 

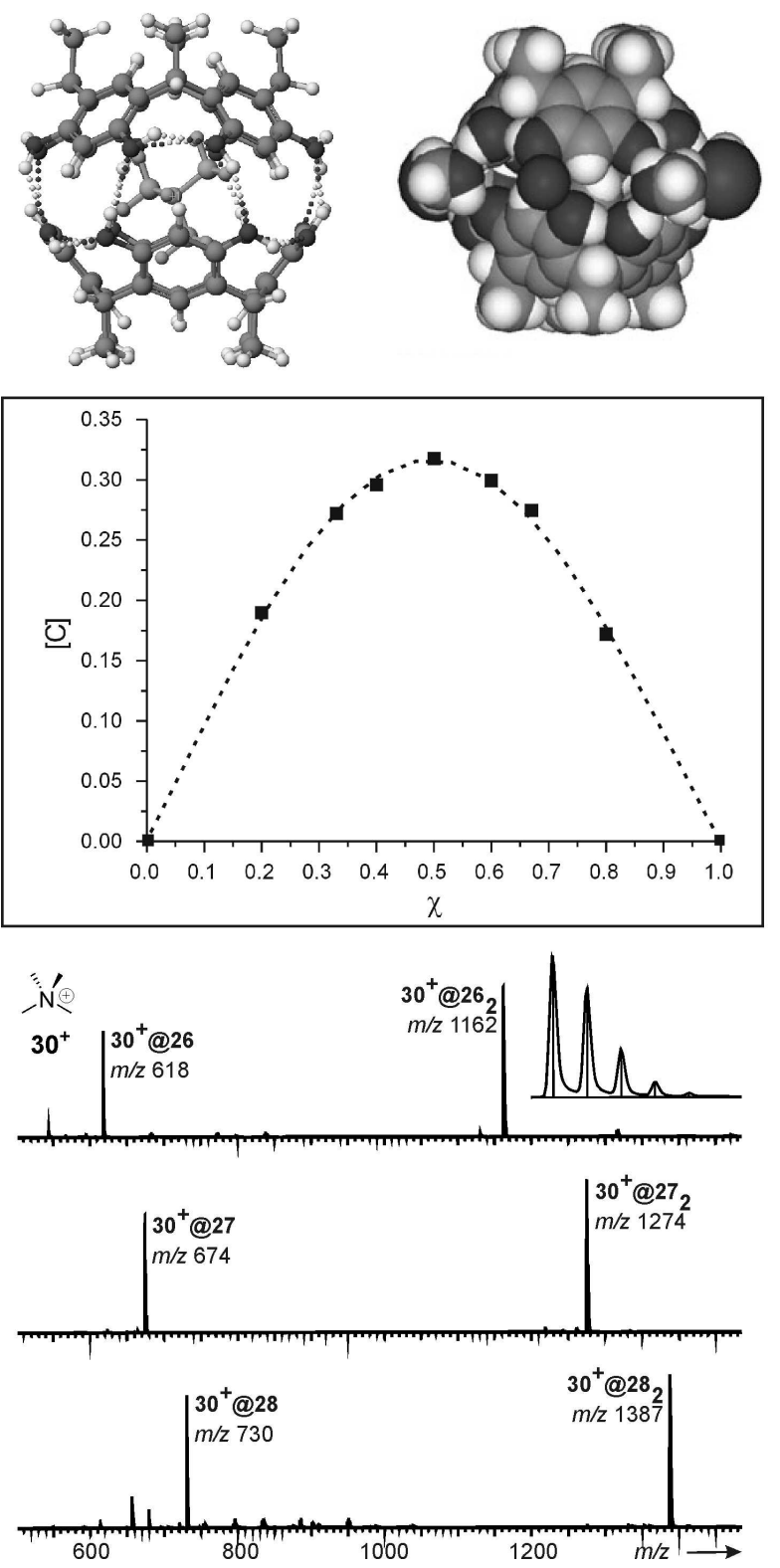

$124 \times 247 \mathrm{~mm}(299 \times 299$ DPI $)$ 


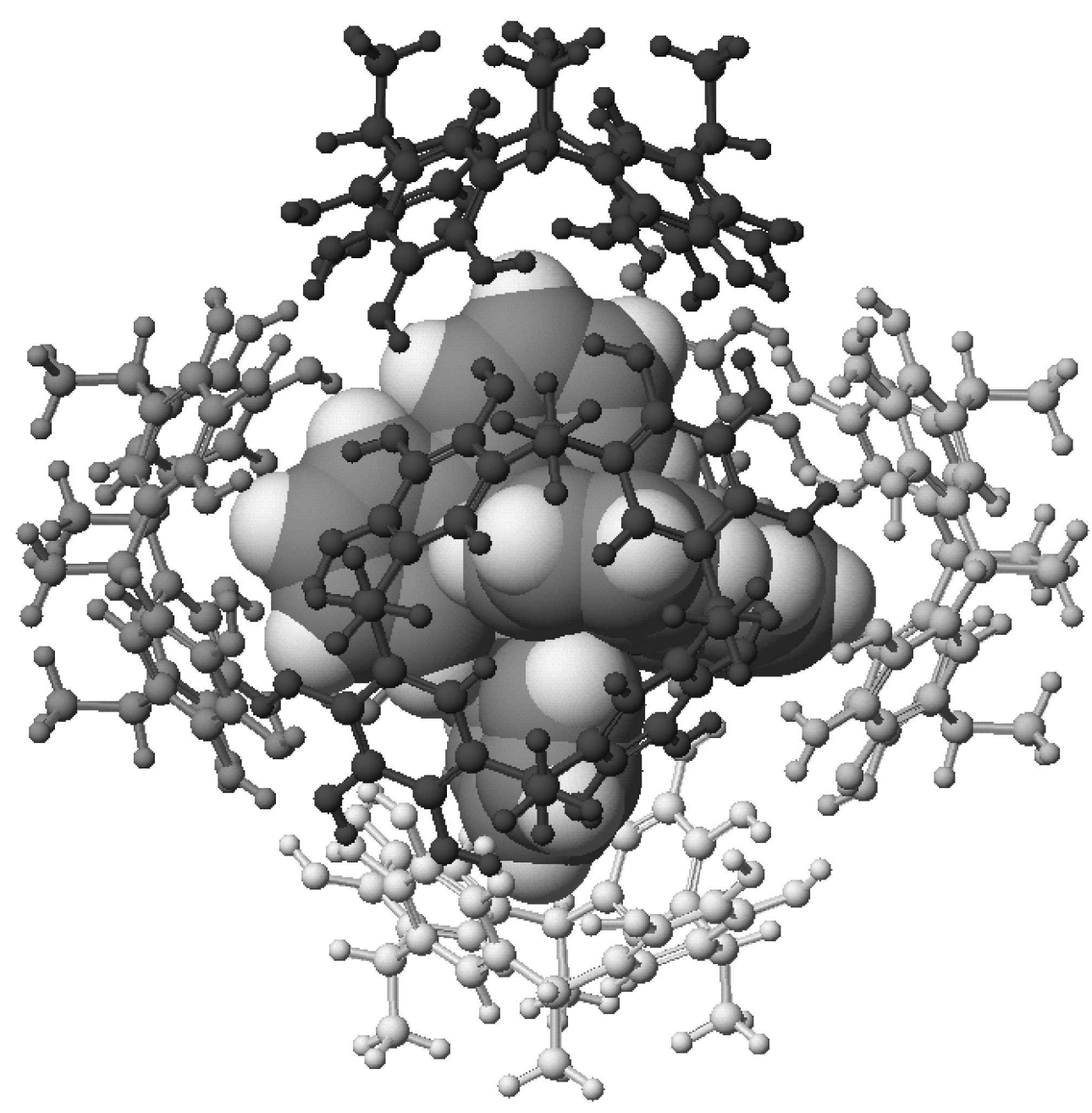

$172 \times 172 \mathrm{~mm}(299 \times 299 \mathrm{DPI})$ 
(a)

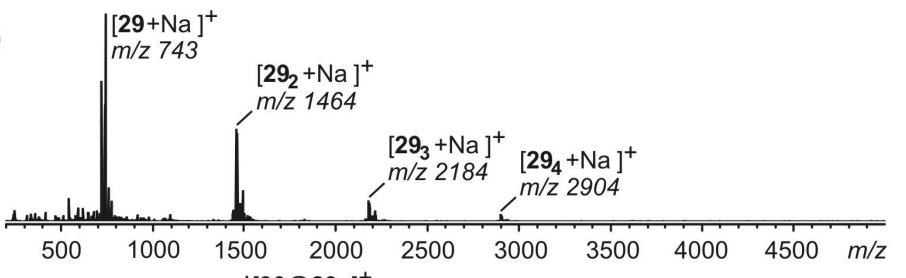

(b)

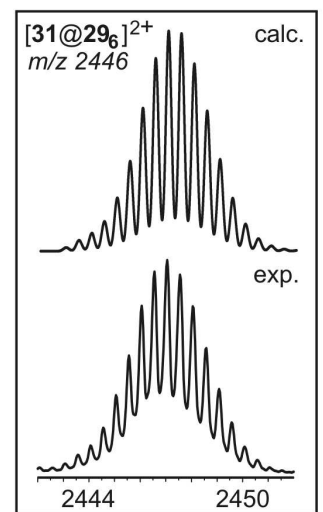

(c)

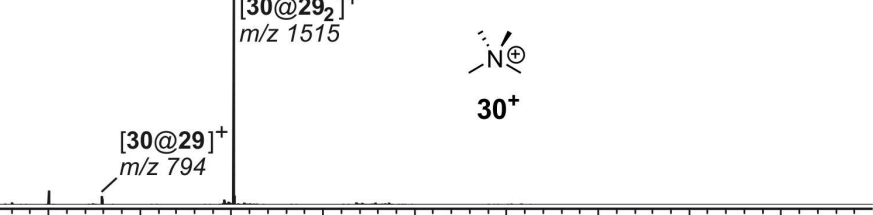

$\mid \begin{aligned} & 8^{+} \\ & m / z 242\end{aligned}$

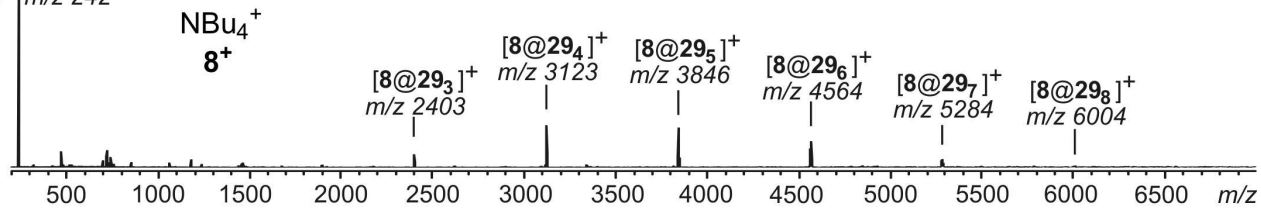

(d) $\begin{array}{ccc}31^{2+} & {\left[31 @ 29_{3}\right]^{2+}} & {\left[31 @ 29_{5}\right]^{2+}} \\ m / z 285 & m / z 1365 & m / z 2086\end{array} \mid \begin{aligned} & {\left[31 @ 29_{6}\right]^{2+}} \\ & m / z 2446\end{aligned}$

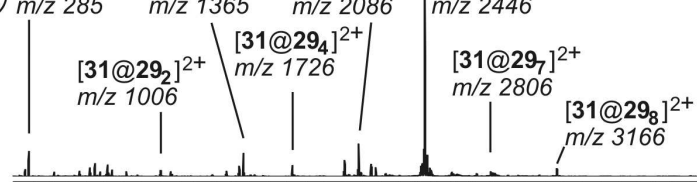

(e) $\left[31 @ 27_{3}\right]^{2+} \quad \begin{aligned} & {\left[31 @ 27_{5}\right]^{2+}} \\ & \mathrm{m} / \mathrm{z} 1786\end{aligned} \mid \begin{aligned} & {\left[31 @ 27_{6}\right]^{2+}} \\ & \mathrm{m} / \mathrm{z} 2086\end{aligned}$
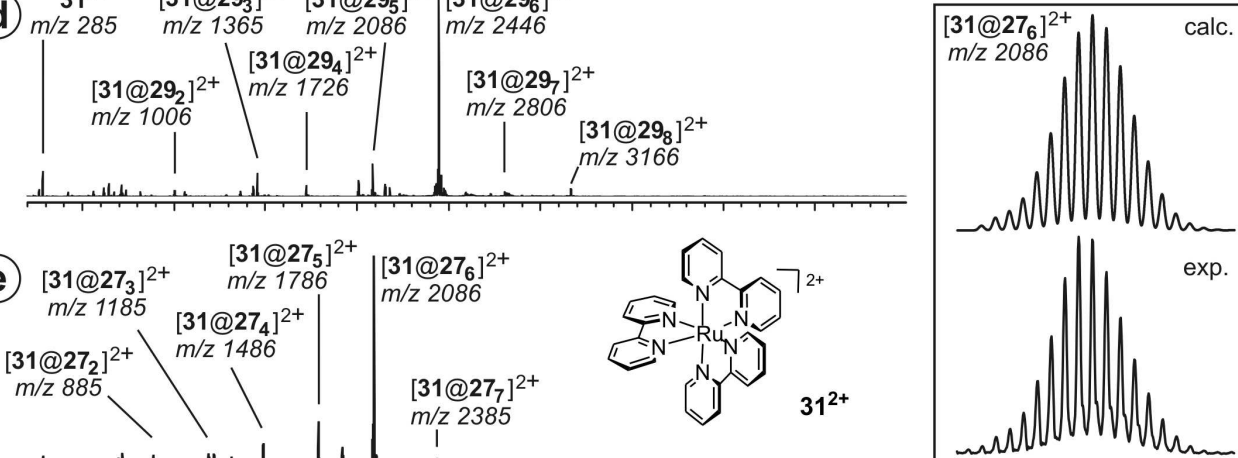

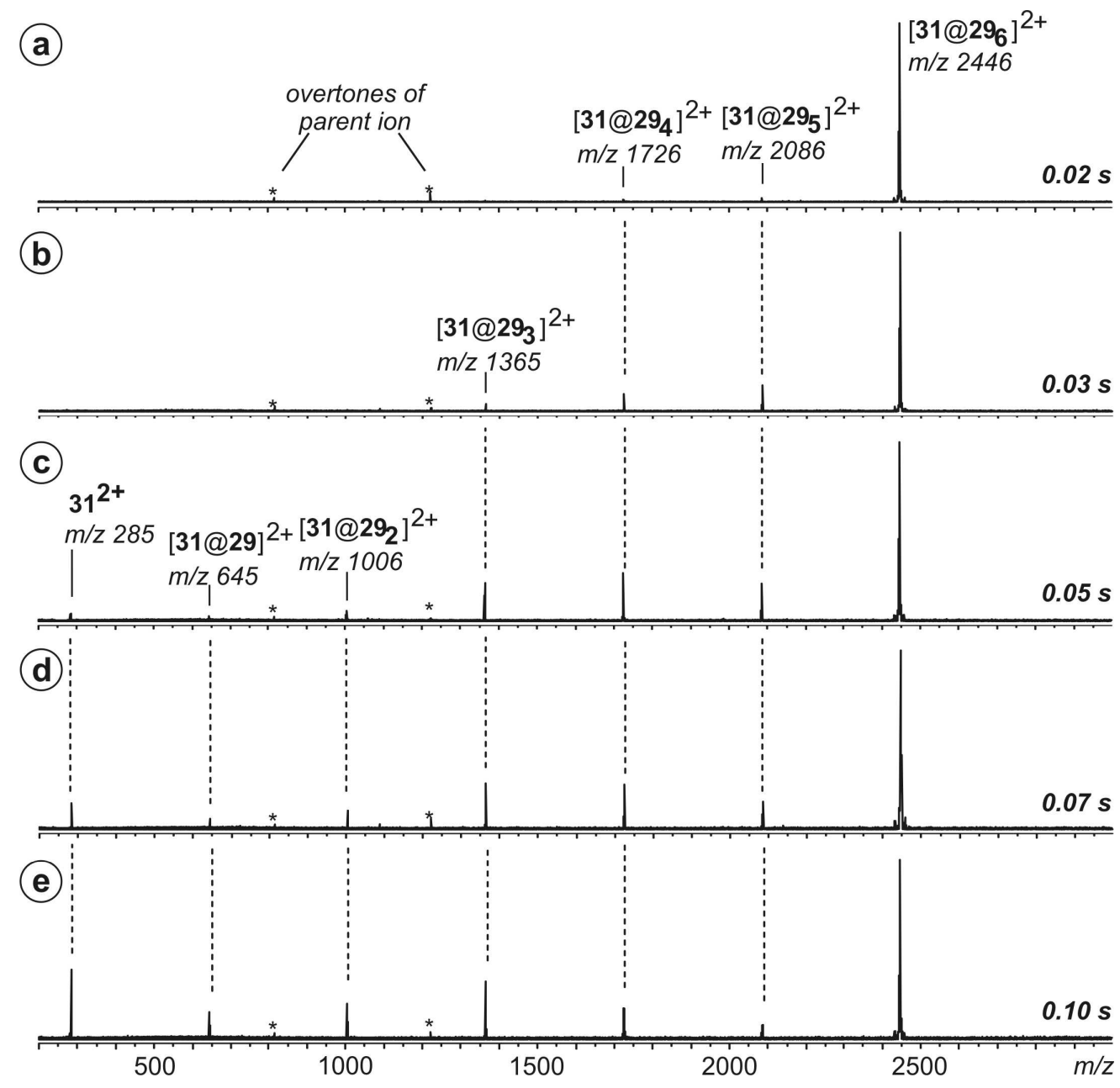

$183 \times 178 \mathrm{~mm}(300 \times 300$ DPI $)$ 